Proceedings

\title{
Oxygen Sensors Based on Thin Films of Gallium Oxide Modified with Silicon ${ }^{+}$
}

\author{
Aleksei V. Almaev 1,*, Evgeniy V. Chernikov ${ }^{2}$, Bogdan O. Kushnarev 1, Nikita N. Yakovlev ${ }^{1}$, \\ Petr M. Korusenko ${ }^{3,4}$ and Sergey N. Nesov ${ }^{3}$ \\ 1 Laboratory of Functional Electronics, Tomsk State University, Tomsk 634050, Russia; \\ kuschnaryow@mail.ru (B.O.K.); nik_mr_x@mail.ru (N.N.Y.) \\ 2 Laboratory of Semiconductor Devices, Kuznetsov Siberian Physical Technical Institute, \\ Tomsk State University, Tomsk 634050, Russia; evvch192184@gmail.com \\ 3 Laboratory of Nanomaterials and Heterostructures, Omsk Scientific Center of Siberian Branch, \\ Russian Academy of Sciences, Omsk 644024, Russia; korusenko@obisp.oscsbras.ru (P.M.K.); \\ nesov@obisp.oscsbras.ru (S.N.N.) \\ 4 Department of Solid State Electronics, St. Petersburg State University, Saint Petersburg 198504, Russia \\ * Correspondence: almaev_alex@mail.ru \\ + Presented at the 6th International Electronic Conference on Sensors and Applications, 15-30 November \\ 2019; Available online: https://ecsa-6.sciforum.net/.
}

Published: 14 November 2019

\begin{abstract}
The results of an investigation of the electrical resistivity of $\mathrm{Ga}_{2} \mathrm{O}_{3}$ thin films modified with silicon under the influence of oxygen in the range of $\mathrm{O}_{2}$ from 9 to 100 vol. $\%$ and changes in the heating temperature of structures from 25 to $700{ }^{\circ} \mathrm{C}$ were presented. Thin films of $\mathrm{Ga}_{2} \mathrm{O}_{3}$ were obtained by RF magnetron sputtering of $\mathrm{Ga}_{2} \mathrm{O}_{3}$ targeted with pieces of $\mathrm{Si}$ on the target's surface in oxygen-argon plasma. The possibility of developing selective oxygen sensors based on thin films $\mathrm{Ga}_{2} \mathrm{O}_{3}$ modified with silicon with a temperature of maximum response $400{ }^{\circ} \mathrm{C}$ was shown. Oxygen influence leads to a reversible increase in the samples' resistance, due to the chemisorption of oxygen on the surface of thin $\mathrm{Ga}_{2} \mathrm{O}_{3}$ films. An increase in the response of sensors based on the thin polycrystalline films of gallium oxide modified with silicon is caused an increase in the adsorption centers for $\mathrm{O}^{-}$, due to an increase in the surface inhomogeneity and the appearance of additional adsorption centers $\mathrm{Si}^{4+}$.
\end{abstract}

Keywords: gallium oxide; thin films; RF-magnetron sputtering; oxygen

\section{Introduction}

It is offered to use high-temperature oxygen sensors based on polycrystalline films and singlecrystal wafers of $\beta-\mathrm{Ga}_{2} \mathrm{O}_{3}$ in a number of papers [1-5]. In the range of working temperatures $T$ from 700 to $1100{ }^{\circ} \mathrm{C}$, oxygen penetrates into the bulk of $\mathrm{Ga}_{2} \mathrm{O}_{3}$, where it interacts with the oxygen vacancies Vo. It was experimentally shown that with increasing oxygen concentration in a mixture of $\mathrm{O}_{2}+\mathrm{N}_{2}$ from 20 to 100 vol. \% sensor's resistance increases $1.04 \div 1.6$ times. The disadvantages of such sensors are high power consumption and relatively weak sensitivity to $\mathrm{O}_{2}$. High operating temperatures make it difficult to develop sensors compatible with other elements of gas analytical systems.

The possibility of creating low-temperature $\mathrm{O}_{2}$ sensors based on $\mathrm{Ga}_{2} \mathrm{O}_{3}$ nanowires was considered in Reference [6]. The sensitivity of the structures to gas was explained by the chemisorption of $\mathrm{O}_{2}$ particles on the semiconductor surface. The authors excluded bulk effects involving of interaction between $\mathrm{O}_{2}$ and $\mathrm{V}_{0}$. The sensor response increased with oxygen concentration according to a power law with an index of 0.57 at a temperature of $300{ }^{\circ} \mathrm{C}$ that 
corresponds to the maximum sensitivity. The high sensitivity to gas at low temperatures was explained by the increase in the ratio between the surface area of a semiconductor and its bulk. In this research, the selective detection of $\mathrm{O}_{2}$ has been experimentally established. The sensitivity of the structures to $\mathrm{O}_{2}$ was investigated in a limited range of oxygen concentration from 0.5 to 5 vol. \%.

Currently, many studies are devoted to silicon doped gallium oxide. Such material is of interest to power electronics. However, the gas-sensitive properties of gallium oxide with the addition of silicon have not been studied. The purpose of this work is to research the gas-sensitive characteristics of $\mathrm{Ga}_{2} \mathrm{O}_{3}$ thin films modified with silicon with exposure to $\mathrm{O}_{2}$. In this work, we denote gallium oxide modified with silicon as $\mathrm{Ga}_{2} \mathrm{O}_{3}-\mathrm{Si}$.

\section{Materials and Methods}

$\mathrm{Ga}_{2} \mathrm{O}_{3}$ thin films were formed by the RF magnetron sputtering of a gallium oxide target $(99.999 \%$ purity, made in the USA) in oxygen-argon plasma using the Edwards A-500 installation. Polycrystalline polished sapphire wafers were used as a substrate. The substrate was not specifically heated. Working chamber pressure and the installation's power capacity were $7 \times 10^{-3} \mathrm{mbar}$ and 70 $\mathrm{W}$, respectively. Oxygen concentration in $\mathrm{Ar}+\mathrm{O}_{2}$ mixture remained at $56.1 \pm 0.5$ vol. \%. Distance between the target and the substrate was $70 \mathrm{~mm}$. It took 20-24 min to sputter one film onto a sapphire substrate. Pieces of Si ( $99.999 \%$ purity) placed on the surface of the target to modify samples. The ratio of the surface areas of the Si pieces and the sputtered part of the target was $3 \times 10^{-3}$. After deposition of $\mathrm{Ga}_{2} \mathrm{O}_{3}$ films, the obtained structures were annealed in an Ar atmosphere for $30 \mathrm{~min}$ at a temperature of $900{ }^{\circ} \mathrm{C}$ to form the $\beta$-phase of $\mathrm{Ga}_{2} \mathrm{O}_{3}$ [7]. The film thickness was $160-180 \mathrm{~nm}$ and was measured by means of a Solver HV atomic force microscope of NT-MDT.

To measure the resistance of the sensors, a metallic chamber with $600 \mathrm{~cm}^{3}$ volume was used. There were two gas sensors into the metallic chamber. A mixture of nitrogen and oxygen of high purity was pumped through the chamber. The content of the gas mixture components was control by Bronkhorst gas flow meters. The gas mixture flow was maintained at a constant $1800 \mathrm{~cm}^{3} / \mathrm{min}$ level. A concentration of 0 vol. \% of $\mathrm{O}_{2}$ corresponds to pumping only nitrogen through the chamber. Measurements of the resistance of the structures were carried out using a Keithley 2636A sourcemeter. The applied voltage to the samples was $5 \mathrm{~V}$. The sensors were heated using a laboratory power source.

The morphology of the surface of the films was studied using a Solver HV atomic force microscope of NT-MDT. The determination of the elemental composition of gallium oxide thin films was carried out using specially manufactured samples of a large area. XPS was conducted on the analytic complexity of the Surface Science Center (Riber). To excite X-ray spectra, AlK $\alpha$ radiation was used $(h v=1487 \mathrm{eV})$. XPS spectra were obtained in an ultrahigh vacuum $\left(\sim 10^{-9} \mathrm{Torr}\right)$ using a two-stage cylindrical mirror analyzer. The energy resolution for the XPS spectra was $\sim .1 \mathrm{eV}$. The structure and phase composition of gallium oxide films was determined by X-ray diffraction analysis using a highprecision Shimadzu XRD-6000 unit (Shimadzu Corporation, Japan).

\section{Results and Discussion}

Using atomic force microscopy, it was found that the surface of the $\mathrm{Ga}_{2} \mathrm{O}_{3}-\mathrm{Si}$ thin films was a more developed surface of $\mathrm{Ga}_{2} \mathrm{O}_{3}$ films and represented by grains of the same shape in the form of thin flakes oriented in the same direction with the characteristic dimensions of 145 and $100 \mathrm{~nm}$. The surface roughness of the $\mathrm{Ga}_{2} \mathrm{O}_{3}-\mathrm{Si}$ films was 0.2345 microns. The surface structure of $\mathrm{Ga}_{2} \mathrm{O}_{3}$ films without additives was represented by irregularly shaped grains with an average characteristic size of $100 \mathrm{~nm}$. The roughness of such films was 0.0783 microns. It should be noted that an increase in grain size was observed for thin films of $\mathrm{Ga}_{2} \mathrm{O}_{3}$ films obtained by $\mathrm{RF}$ magnetron sputtering and upon doping with $\mathrm{Nb}$ and $\mathrm{W}[8,9]$. From our results, it follows that modifying of films with silicon promoted the formation of larger grains of $\mathrm{Ga}_{2} \mathrm{O}_{3}$. However, in general, the surface of the film was more embossed, i.e., the specific surface area in contact with oxygen increases. 
According to XRD analysis, the samples consisted of $\beta$-phase gallium oxide polycrystals (Figure 1) [10]. Also, according to XRD, there were two intense peaks associated with sapphire $[10,11]$. For the $\mathrm{Ga}_{2} \mathrm{O}_{3}-\mathrm{Si}$ films, there were peaks corresponding to $\mathrm{SiO}_{2}$ (114) and (222).
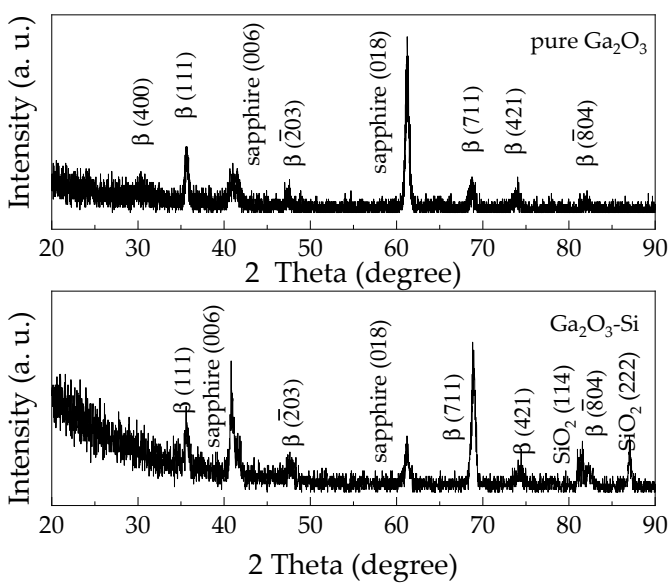

Figure 1. $\mathrm{XRD}$ pattern of the pure $\mathrm{Ga}_{2} \mathrm{O}_{3}$ and $\mathrm{Ga}_{2} \mathrm{O}_{3}-\mathrm{Si}$ thin films.

XPS analysis of the samples of the pure $\mathrm{Ga}_{2} \mathrm{O}_{3}$ and $\mathrm{Ga}_{2} \mathrm{O}_{3}-\mathrm{Si}$ showed that spectra contain followings lines: Gallium Ga 2p-1118 eV, the Ga LMM Auger transition-598-370 eV, Ga 3p-105 eV, $\mathrm{Ga} 3 \mathrm{~d}-20 \mathrm{eV}$, oxygen O 1s-530 eV, the O KLL Auger transition-1000-960 eV. The energy position of the Ga $2 \mathrm{p}$ and $\mathrm{Ga} 3 \mathrm{~d}$ lines indicated that the thin films correspond in composition to $\mathrm{Ga}_{2} \mathrm{O}_{3}$. The analysis of silicon in $\mathrm{Ga}_{2} \mathrm{O}_{3}$ was difficult, due to the overlap of the $\mathrm{Si} 2 \mathrm{p}$ and $\mathrm{Ga} 3 \mathrm{p}$ lines. However, in the spectrum of the sample of $\mathrm{Ga}_{2} \mathrm{O}_{3}-\mathrm{Si}$ after annealing, there was a slight increase in the signal intensity in the $\mathrm{Si} 2 \mathrm{p}$ region. In this case, silicon was probably in the oxidized state of $\mathrm{SiO}_{\mathrm{x}}(1<\mathrm{x}<2)$. It was not possible to determine the concentration of silicon in the samples because of its low value. It was previously noted that when doping $\mathrm{Ga}_{2} \mathrm{O}_{3}$ films obtained by magnetron sputtering with $\mathrm{Si}$, silicon oxide was not formed [12]. In this research, annealing was carried out under other conditions.

Quantitative XPS analysis of the samples showed that for the pure $\mathrm{Ga}_{2} \mathrm{O}_{3}$ thin films, an $\mathrm{O} / \mathrm{Ga}$ ratio was 1.37. Stoichiometric $\mathrm{Ga}_{2} \mathrm{O}_{3}$ possess an $\mathrm{O} / \mathrm{Ga}$ ratio of 1.5 . The $\mathrm{O} / \mathrm{Ga}$ ratio in $\mathrm{Ga}_{2} \mathrm{O}_{3}$ films depends on the sputtering conditions [13]. It should be noted that the obtained films of the pure $\mathrm{Ga}_{2} \mathrm{O}_{3}$ were close to stoichiometric. The $\mathrm{Ga}_{2} \mathrm{O}_{3}-\mathrm{Si}$ thin films were characterized by an $\mathrm{O} / \mathrm{Ga}$ ratio of 1.06 . That is, gallium oxide films are characterized by a lack of oxygen. The oxygen content in the films mainly depends on the annealing conditions. We believed that a significant deviation from stoichiometry for the $\mathrm{Ga}_{2} \mathrm{O}_{3}-\mathrm{Si}$ thin films towards a decrease in the oxygen content was caused by an increase in the specific surface of the films upon modified with silicon. Under conditions of hightemperature annealing in an argon atmosphere, the probability of desorption of lattice oxygen Oo rose with an increase in the specific surface of the films.

Figure 2 shows the change in the electrical resistance of the two sensors based on the $\mathrm{Ga}_{2} \mathrm{O}_{3}-\mathrm{Si}$ thin films at exposure to $44.5 \mathrm{vol} . \%$ of oxygen and at $T=600{ }^{\circ} \mathrm{C}$. Sensors were initially located in a nitrogen atmosphere. Differences in the characteristics of sensors, their kinetics, response values, response and recovery times were caused by the disadvantages of magnetron sputtering technology of thin films. However, the regularities for the sensors obtained on one plate were the same. The sources of differences of samples can be the heterogeneous distribution of silicon, different concentration of local defects, minor differences in the area and thickness of films, etc. Oxygen influence on sensors led to reversible changes in their resistance. It was discovered that in the 300$700{ }^{\circ} \mathrm{C}$ temperature range after pumping oxygen out of the chamber, the resistance of the samples was fully recovered. At $T \leq 300^{\circ} \mathrm{C}$ accuracy of measuring instruments' readings was significantly impacted by noises, due to high resistance of the sensors. At higher temperature ranges $\left(300-700^{\circ} \mathrm{C}\right)$, the sensors have significant reproducibility of the characteristics.

To evaluate the performance of sensors, the response and recovery times were estimated. The response time $t_{r e s}$ is the time period during which sensor resistance reaches $0.9 R s_{s t}$ level after the 
beginning of oxygen exposure, where $R_{\text {sst }}$ is sensor resistance stationary value at $44.5 \mathrm{vol} . \%$ of oxygen concentration. The recovery time $t_{\text {rec }}$ denotes the time interval during which sensor resistance reaches level $1.1 R_{0 s t}$, where $R_{0 s t}$ is sensor's stationary resistance value in the nitrogen atmosphere. The shortest response time for sensors was observed at $T=600^{\circ} \mathrm{C}$ and was $11-13 \mathrm{~s}$. The recovery time was $70-80 \mathrm{~s}$.

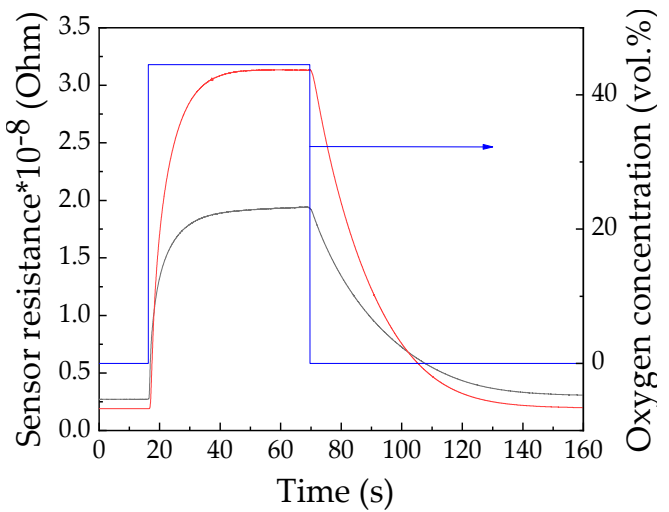

Figure 2. Time dependence of resistance of sensors based on the $\mathrm{Ga}_{2} \mathrm{O}_{3}-\mathrm{Si}$ thin films at exposure to 44.5 vol. $\%$ of $\mathrm{O}_{2}$ and at $T=600{ }^{\circ} \mathrm{C}$.

The following relation was chosen as the sensor response $S$ to oxygen:

$$
S=R_{s}(C) / R_{N}
$$

where $C$ is the oxygen concentration; $R_{s}(C)$ is the electrical resistance of the samples in the gas mixture $\mathrm{O}_{2}+\mathrm{N}_{2} ; R_{\mathrm{N}}$ is the electrical resistance of the samples in the nitrogen atmosphere. The samples were not practically subjected to oxygen exposure in the temperature range from room temperature to $200^{\circ} \mathrm{C}$. Starting from a temperature of $200^{\circ} \mathrm{C}, \mathrm{Ga}_{2} \mathrm{O}_{3}-\mathrm{Si}$ exhibited sensitivity to $\mathrm{O}_{2}$. Temperature dependences of the sensor response to oxygen concentrations 44.5 and 100 vol. \% in the temperature range from 200 to $700{ }^{\circ} \mathrm{C}$ are shown in Figure 3. There was a pronounced maximum of the sensor response to oxygen on the curves at $T=400{ }^{\circ} \mathrm{C}$. Such temperature of the maximum response is much lower than in References [1-5], but higher than in Reference [6]. The response of the sensors decreased with a further increase in temperature. However, at $T=700{ }^{\circ} \mathrm{C}$, for all oxygen concentrations, a slight increase in the response of the $\mathrm{Ga}_{2} \mathrm{O}_{3}-\mathrm{Si}$ structures was observed.

The response of sensors with increasing oxygen concentration rose according to the power law $S \sim C^{m}$ at all temperatures chosen for research (Figure 4). The value of the index $m$ depends on the temperature. At a temperature $400{ }^{\circ} \mathrm{C} m=0.86 \pm 0.02$ and at $T=500 \div 700{ }^{\circ} \mathrm{C} m=0.61 \pm 0.04$.

Evaluation of the effect of $\mathrm{H}_{2}$ and $\mathrm{CO}$ on the resistance of $\mathrm{Ga}_{2} \mathrm{O}_{3}-\mathrm{Si}$ was carried out at a temperature corresponding to the maximum response to oxygen. A mixture containing $21 \mathrm{vol} . \%$ of $\mathrm{O}_{2}$ and 79 vol. \% of $\mathrm{N}_{2}$ was chosen as the initial medium. Impact of 1.55 vol. \% of $\mathrm{H}_{2}$ and $160 \mathrm{ppm}$ of $\mathrm{CO}$ led to a slight decrease in $R_{s}$ by 1.9 and 1.1 times, respectively. Exposure to $71 \mathrm{ppm}$ nitrogen dioxide led to an increase in film resistance by 10 times. It follows from this that under the established conditions, the $\mathrm{Ga}_{2} \mathrm{O}_{3}-\mathrm{Si}$ thin films react poorly to the exposure to high concentrations exceeding the maximum permissible limits of reducing gases. However, the resistance of the $\mathrm{Ga}_{2} \mathrm{O}_{3}-\mathrm{Si}$ thin films increased sharply when oxidizing gases appear in the atmosphere.

The obtained dependence of the sensor response on the oxygen concentration can be explained by the chemisorption of oxygen on the surface of thin $\mathrm{Ga}_{2} \mathrm{O}_{3}$ films. In the temperature range from 300 to $700{ }^{\circ} \mathrm{C}$ oxygen was chemisorbed on the $\mathrm{Ga}_{2} \mathrm{O}_{3}$ surface, mainly in atomic form and captured an electron from the conduction band of gallium oxide [14]. According to XPS analysis, the $\mathrm{Ga}_{2} \mathrm{O}_{3}-\mathrm{Si}$ films were characterized by a significant deviation from stoichiometry. The surface and bulk of $\mathrm{Ga}_{2} \mathrm{O}_{3}-\mathrm{Si}$ thin films were saturated with superstoichiometric gallium atoms $\mathrm{Ga}^{3+}$. In addition, superstoichiometric silicon atoms $\mathrm{Si}^{4+}$ were present on the surface of the $\mathrm{Ga}_{2} \mathrm{O}_{3}$ thin films. Superstoichiometric gallium $\mathrm{Ga}^{3+}$ and $\mathrm{Si}^{4+}$ atoms on the surface of a gallium oxide film acted as adsorption centers for oxygen atoms and molecules. An increase in the index $m$ and the sensor response at temperature range $350-500{ }^{\circ} \mathrm{C}$ was caused by the influence of $\mathrm{Si}^{4+}$ and a reaction with 
oxygen at these temperatures. A decrease in the response of sensors at temperatures above $500{ }^{\circ} \mathrm{C}$ (Figure 3) was caused by the formation of a $\mathrm{SiO}_{2}$.

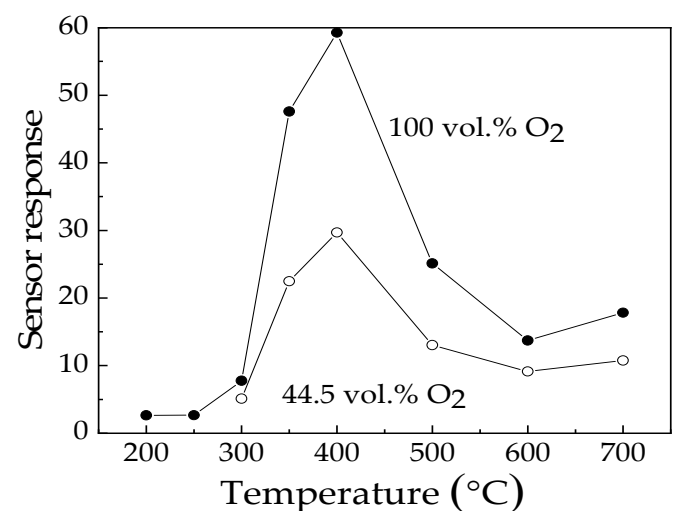

Figure 3. Temperature dependence of the sensor response to oxygen.

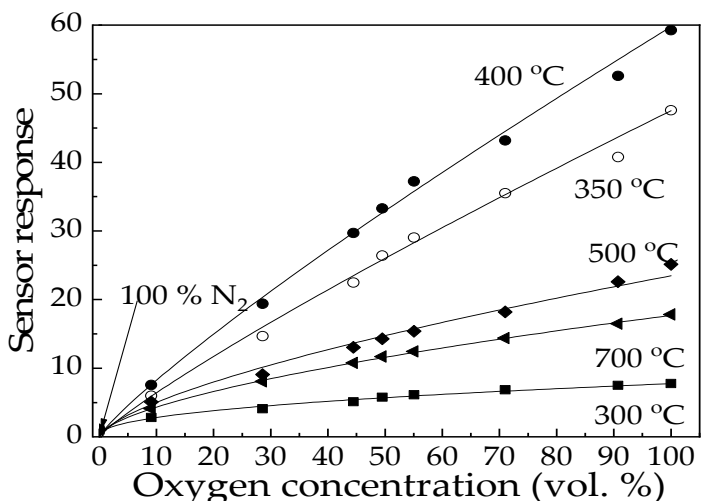

Figure 4. Dependence of the sensor response on the oxygen concentration.

The negative charge of oxygen ions on the $\mathrm{Ga}_{2} \mathrm{O}_{3}$ surface, which, due to the high concentration of intrinsic and introduced defects, is an n-type semiconductor, caused the energy bands to bend upward. In this case, a space charge region was formed, depleted in the main charge carrierselectrons. The energy band bending $e \varphi_{s} \sim N_{i}{ }^{2}$, where $N_{i}$ is the surface density of oxygen ions $\mathrm{O}^{-}$ chemisorbed on gallium oxide films. In this case, the resistance and response of the sensors to oxygen are proportional to $e \varphi_{s}$. An increase in $N_{i}$ during oxygen chemisorption leads to an increase in $e \varphi_{s}$ and a corresponding increase in resistance. An increase in the sensor response upon the modification of thin gallium oxide films by silicon is caused by an increase in the adsorption centers for $\mathrm{O}^{-}$due to an increase in the surface inhomogeneity and the appearance of additional adsorption centers $\mathrm{Si}^{4+}$.

\section{Conclusions}

Thus, the possibility of creating oxygen sensors based on $\mathrm{Ga}_{2} \mathrm{O}_{3}-\mathrm{Si}$ thin films prepared by the method of RF magnetron sputtering is shown. It was discovered that the obtained films correspond to $\beta$-phase of gallium oxide. The studied structures demonstrate sensitivity to oxygen from 9 to $100 \mathrm{vol}$. $\%$. The maximum response of the structures is observed at $400{ }^{\circ} \mathrm{C}$. Oxygen influence leads to a reversible increase in the samples' resistance, due to chemisorption of oxygen $\mathrm{O}^{-}$on the surface of thin $\mathrm{Ga}_{2} \mathrm{O}_{3}$ films. An increase in the response of sensors based on the thin polycrystalline films of gallium oxide modified with silicon is caused an increase in the adsorption centers for $\mathrm{O}^{-}$, due to an increase in the surface inhomogeneity and the appearance of additional adsorption centers $\mathrm{Si}^{4+}$. The oxygen reaction with $\mathrm{Si}^{4+}$ takes place in the temperature range of $350-500{ }^{\circ} \mathrm{C}$. 
Author Contributions: Conceptualization, software, validation, formal analysis, data curation, writingoriginal draft preparation, writing-review and editing, supervision, project administration, funding acquisition, A.V.A.; methodology, A.V.A., E.V.C., and B.O.K.; investigation, A.V.A., N.N.Y., P.M.K., and S.N.N.; resources, A.V.A., and E.V.C.; visualization, A.V.A., and N.N.Y.

Funding: The reported study was funded by the Russian Foundation for Basic Research according to the research project No. 18-32-00456.

Conflicts of Interest: The authors declare no conflict of interest. The funders had no role in the design of the study; in the collection, analyses, or interpretation of data; in the writing of the manuscript, or in the decision to publish the results.

\section{References}

1. Bartic, M.; Ogita, M.; Isai, M.; Baban, C.-L.; Suzuki, H. Oxygen sensing properties at high temperatures of $\beta-\mathrm{Ga}_{2} \mathrm{O}_{3}$ thin films deposited by the chemical solution deposition method. J. Appl. Phys. 2007, 102, 023709.

2. Bartic, M.; Toyoda, Y.; Baban, C.-L.; Ogita, M. Oxygen sensitivity in gallium oxide thin films and single crystals at high temperatures. Jpn. J. Appl. Phys. 2006, 45, 5186.

3. Baban, C.; Toyoda, Y.; Ogita, M. Oxygen sensing at high temperatures using $\mathrm{Ga}_{2} \mathrm{O}_{3}$ films. Thin Solid Films 2005, 484, 369-373.

4. Ju, L.-T.; Ju, S.-L. Deposition of $\mathrm{Ga}_{2} \mathrm{O}_{3}$ thin film for high-temperature oxygen sensing applications. J. Ovonic Res. 2012, 8, 73-79.

5. Bartic, M. Mechanism of oxygen sensing on $\beta-\mathrm{Ga}_{2} \mathrm{O}_{3}$ single-crystal sensors for high temperatures. Phys. Stat. Solidi A 2016, 213, 457-462.

6. Liu, Z.; Yamazaki, T.; Shen, Y.; Kikuta, T.; Nakatani, N.; Li, Y. O 2 and CO sensing of Ga2 $\mathrm{O}_{3}$ multiple nanowire gas sensors. Sens. Actuators B Chem. 2008, 129, 666-670.

7. Lygdenova, T.Z.; Kalygina, V.M.; Novikov, V.A.; Prudaev, I.A.; Tolbanov, O.P.; Tyazhev, A.V. Properties of gallium oxide films obtained by HF-magnetron sputtering. Russ. Phys. J. 2018, 60, 1911-1916.

8. Zhang, H.; Deng, J.; Pan, Z.; Bai, Z.; Kong, L.; Wang, J. Structural and optical properties of Nb-doped $\beta$ $\mathrm{Ga}_{2} \mathrm{O}_{3}$ thin films deposited by RF magnetron sputtering. Vacuum 2017, 146, 93-96.

9. Rubio, E.J.; Mates, T.E.; Manandhar, S.; Nandasiri, M.I.; Shutthanandan, V.; Ramana, C.V. Tungsten incorporation into gallium oxide: Crystal structure, surface and interface chemistry, thermal stability and interdiffusion. J. Phys. Chem. C 2016, 120, 47, 26720-26735.

10. Kim, H.W.; Kim, N.H. Annealing effects on the properties of $\mathrm{Ga}_{2} \mathrm{O}_{3}$ thin films grown on sapphire by the metal organic chemical vapor deposition. Appl. Surf. Sci. 2004, 230, 301-306.

11. Golubovic, A.; Slobodanka, N.; Djuric, S.; Valcic, A. The growth of sapphire single crystals. J. Serb. Chem. Soc. 2001, 66, 411-418.

12. Takakura, K.;Koga, D.; Ohyama, H.; Rafi, J.M.; Kayamoto, Y.; Shibuya, M.; Yamamoto, H.; Vanhellemont, J. Evaluation of the crystalline quality of $\beta-\mathrm{Ga}_{2} \mathrm{O}_{3}$ films by optical absorption measurements. Phys. B 2009, $404,4854-4857$.

13. Saikumar, A.K.; Nahate, S.D.; Sundaram, K.B. Review-RF sputtered films of Ga2O3. ECS J. Solid State Sci. Technol. 2019, 8, Q3064-Q3078.

14. Fleischer, M.; Giber, J.; Meixner, $\mathrm{H}$. $\mathrm{H}_{2}$-induced changes in electrical conductance of $\beta-\mathrm{Ga}_{2} \mathrm{O}_{3}$ thin-film systems. Appl. Phys. A 1992, 54, 560-566.

(C) 2019 by the authors. Licensee MDPI, Basel, Switzerland. This article is an open access article distributed under the terms and conditions of the Creative Commons Attribution (CC BY) license (http://creativecommons.org/licenses/by/4.0/). 